\title{
The Changing Demography of Rural and Small-Town America
}

\author{
Tim Slack $^{1}$ (D) $\cdot$ Leif Jensen ${ }^{2}$
}

Received: 19 August 2020 / Accepted: 23 August 2020 / Published online: 14 September 2020

(c) Springer Nature B.V. 2020

\begin{abstract}
The rural United States is sometimes viewed as a paragon of stability, but demographic change has been a constant. Rural and small-town America is diverse, dynamic, and relational to (rather than separate from) urban places. Dominant demographic trends in the rural U.S. over recent decades include depopulation (driven by population aging and youth out-migration), increasing ethnoracial diversity (especially as linked to Hispanic population growth), and in-migration to select areas associated with metropolitan adjacency (i.e., exurban growth), retirement destinations, and natural amenities. This special issue of Population Research and Policy Review assembled a group of papers focused squarely on the changing demography of rural and small-town America in the early twenty-first century that address issues of broad interest to demographers: population growth and decline, fertility, mortality, migration, ethnoracial composition, and economic inequality. The prospect is for a rural America marked by ever more diversity and inequality within and between places. Our hope is that these articles, and the broader spectrum of scholarship on rural demography they represent, will inspire the next generation of research in this area.
\end{abstract}

Keywords Rural demography $\cdot$ Fertility $\cdot$ Mortality $\cdot$ Migration $\cdot$ Population change

The contemporary United States is a decidedly urban nation. For more than a century the increasing concentration of the U.S. population in the metropolis and the spatial expansion of cities through suburbanization have comprised "a master

Tim Slack

slack@1su.edu

Leif Jensen

lij1@psu.edu

1 Department of Sociology, Louisiana State University, Stubbs Hall, Baton Rouge, LA 70803, USA

2 Department of Agricultural Economics, Sociology, and Education, The Pennsylvania State University, Armsby Building, University Park, PA 16802, USA 
demographic trend" (Lichter and Ziliak 2017, p. 16). Today, not only are metropolitan areas the context in which most Americans reside, they are the centers of power for economic, political, and media interests. The net result is that most people's lived experience, the popular definition of social issues, public policy, and media portrayals of American life are all urbancentric. In part, this is why the 2016 presidential election of Donald Trump came as a surprise to so many, when he garnered disproportionate support from the millions of Americans who continue to live and work outside the nation's major cities. Trump's strong performance in rural areas-which are typically Republican strongholds - combined with especially pivotal votes in smaller Rust Belt cities, allowed him to edge out Hillary Clinton in the Electoral College (Monnat and Brown 2017). Flyover country had demanded notice.

This special issue of Population Research and Policy Review addresses this national blind spot by highlighting the changing demography of the rural U.S. The fact that rural areas and small towns are home to many Americans is, of course, not new. During the nation's early history, the vast majority of the U.S. population was rural-at the beginning of the nineteenth century, nearly $95 \%$ of the populace lived in rural areas (Iceland 2014)—with people primarily employed in economies focused on agriculture and natural resource extraction. In the late 19th and early twentieth centuries, the U.S. population was transformed by the interrelated processes of industrialization, urbanization, immigration from abroad, and internal rural-to-urban migration. By 1920, the U.S. population crossed the threshold from majority rural to majority urban (U.S. Census Bureau 2015), and by mid-century transitioned from Americans living primarily in nonmetropolitan (nonmetro) to metropolitan (metro) counties (Gibson 2012). As of the 2010 decennial census, about $19 \%$ of Americans lived in rural areas and $14 \%$ lived in nonmetro counties (Cromartie 2017; U.S. Census Bureau 2020). ${ }^{1}$

Despite these trends in population redistribution, nonmetro areas continue to account for over 70\% of the nation's land area (Cromartie 2017). Moreover, while quaint notions of rural conjure images of farms and culturally homogeneous villages, rural and small-town America is and always has been diverse, dynamic, and relational to (rather than separate from) urban places (Bailey et al. 2014; Lichter and Brown 2011; Lichter and Ziliak 2017). Dominant demographic trends in the rural U.S. over recent decades include depopulation (driven by population aging and youth out-migration), increasing ethnoracial diversity (especially as linked to Hispanic population growth), and in-migration to select areas associated with metropolitan adjacency (i.e., exurban growth), retirement destinations, and natural amenities (Brown 2014). Though once dependent upon agriculture and natural resource extraction-activities that continue to be dominant in some areas-rural America has also become increasingly economically varied. Today, agricultural and extractive industries (e.g., mining) account for less than 5\% of nonmetro employment, while manufacturing, trade, and services provide most jobs (Cromartie 2017). Importantly, although the popular discourse often casts big cities and small towns as divided, and researchers frequently structure their analyses to treat urban and rural as separate

1 The terms "rural" and "nonmetro" are defined in the following section. 


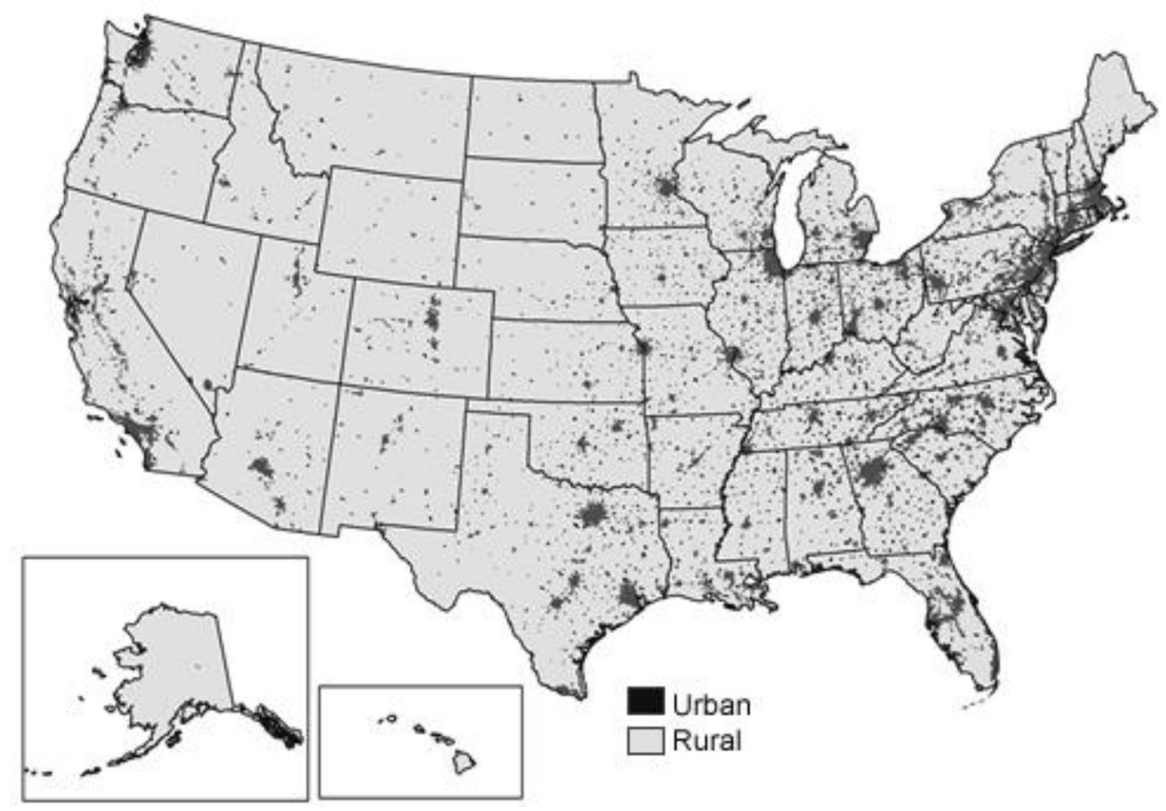

Fig. 1 Urban and rural areas, 2012. Source USDA, Economic Research Service

comparative categories, the rural-urban continuum today is actually more integrated and interdependent socially and economically than ever before (Bailey et al. 2014; Lichter and Brown 2011; Lichter and Ziliak 2017).

\section{What is Rural?}

Just as popular meanings of rural and urban differ widely, rural social demographers use a variety of definitions in their research. The U.S. Department of Agriculture (USDA), Economic Research Service (ERS) is a national authority on social and economic trends in rural America and provides an excellent overview of official definitions which we summarize below (2019). The U.S. Census Bureau defines urban as communities with a population of 2500 or more and the densely settled areas around them. Rural is then defined as what urban is not-communities with a population of less than 2500 and open-country settings (see Fig. 1). More widely used in rural population research, however, are the concepts of metro and nonmetro areas. Defined by the U.S. Office of Management and Budget (OMB), this scheme is based on counties and county-equivalents (e.g., parishes). Metro areas are defined as: (1) central counties with one or more urbanized areas of 50,000 or more people; and (2) outlying counties that are economically tied to the core counties by labor-force commuting. Nonmetro is again defined as the residual, characterizing counties that do not fit the metro definition (see Fig. 2). These rural-urban and metro-nonmetro definitions are not mutually exclusive, with rural and urban places existing within 


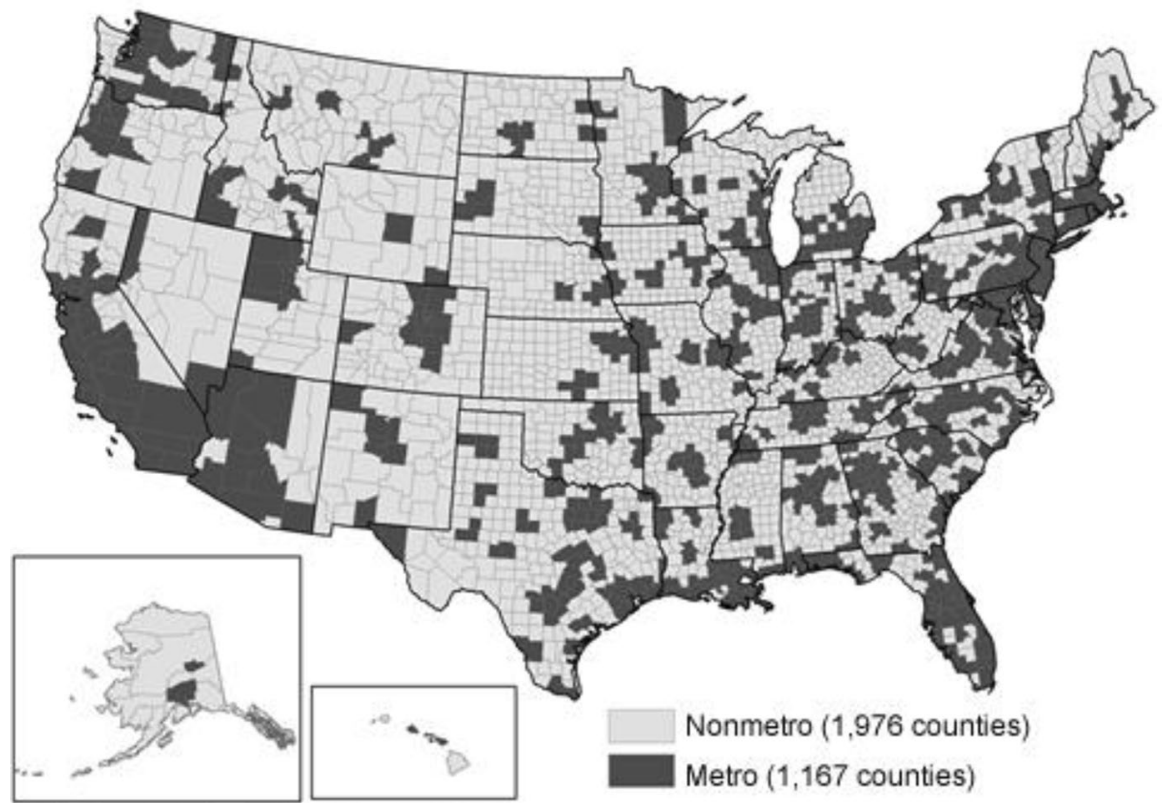

Fig. 2 Metro and nonmetro counties, 2013. Source USDA, Economic Research Service

metro and nonmetro counties. In fact, over half (54.4\%) of Americans living in rural areas reside in metro counties (U.S. Census Bureau 2020).

Nonmetro areas can be further subdivided into micropolitan (micro) and noncore areas. Micro counties are labor-market areas centered on urban clusters of 10,000-49,999 people, while noncore areas are all other (nonmicro) nonmetro counties. Developed in 1975 (Hines et al. 1975), the ERS also produces the Rural-Urban Continuum Codes (sometimes called "Beale Codes" in homage to longtime ERS geographer Calvin Beale), which currently uses nine categories to distinguish between metro areas by population size, and nonmetro areas by degree of urbanization and adjacency to metro areas. Many of the articles in this special issue use some variation of these schemes. Sometimes researchers will use the terms rural and nonmetro interchangeably for ease of exposition, though it is important that readers remain mindful of the distinction.

While rural-urban space, variously defined, represents a critical axis along which to examine social and population processes, rural places are too often neglected by social scientists entirely. Like the broader society, American social science is markedly urbancentric. Two groups that provide a counterweight to this tendency-and that many of the contributors to this issue participate in-are the Rural Sociological Society (RSS) and a long-standing USDA Multistate Research Project of interdisciplinary rural population scholars (currently W4001). The RSS, established in 1937, is a professional social science association dedicated to the generation, application, and dissemination of sociological knowledge on rural life. The Multistate Research Project has also been in existence for decades, and while consistently devoted to 
rural demography it redefines a more specific point of focus every 5 years (at present the group's focus is the Social, Economic, and Environmental Causes and Consequences of Demographic Change in Rural America). We encourage interested readers to seek out opportunities in both these communities of scholarship.

\section{Structure of the Special Issue}

Rural America is sometimes viewed as a paragon of stability when, as the above accounting should make clear, change has been a constant. Tracing back decades, major studies of rural demography have made this point repeatedly. "Nonmetropoli$\tan$ America is in a state of transition as unanticipated and dramatic changes sweep the countryside" (Alonso 1981, p. xv). "Rural and small town America has undergone fundamental economic and social change in recent years" (Fuguitt et al. 1989, p. 1). "Change rather than stability, most accurately characterizes rural America" (Kandel and Brown 2006). This special issue of PRPR echoes these themes. We have assembled a group of papers focused squarely on the changing demography of rural and small-town America in the early twenty-first century that address issues of broad interest to demographers_-population growth and decline; fertility; mortality; migration; ethnoracial composition; and economic inequality-with special attention to changes across rural and urban space. The studies that comprise this issue are summarized below.

As a nation of immigrants, Americans are acutely aware of the impact that immigrants and their descendants have as they move to and within the United States. A demographic reality less widely recognized is that births now exceed deaths in many rural communities across the country. Daniel Lichter and Kenneth Johnson draw these issues together to ask whether immigration can save rural and smalltown America. In "A Demographic Lifeline? Immigration and Hispanic Population Growth in Rural America," they analyze county-level data on population change, natural increase, and net migration for all nonmetro and metro counties from 1990 to 2017. They find that Hispanic population growth has been common across nonmetro counties. In some rural areas, Hispanic gains have been sufficient to keep the area growing, in many others it has slowed but not reversed population declines. White depopulation is now widespread due to decades of rural out-migration and low rates of natural increase, especially in the post-2010 period. They also document heterogeneity across nonmetro America, identifying some places where the metaphor of a demographic lifeline from Hispanic growth holds. The provocative implication is that the attraction of immigrant groups might well be a viable rural development strategy.

Death is not supposed to occur in the prime of life, but it does, and it does so with greater relative frequency in nonmetro America. In "Trends in U.S. Working-Age Non-Hispanic White Mortality: Rural-Urban and Within-Rural Differences," Shannon Monnat analyzes 30 years of data from the National Vital Statistics System to explore mortality trends among non-Hispanic whites aged 25-64 since 1990. Examining deaths from all causes and specific causes, Monnat documents and describes a rural mortality penalty that is real, complex, and worsening. Interestingly, some 
causes of death (e.g., heart disease) have been declining less in nonmetro than metro areas, while others (e.g., suicide) have been rising faster in the countryside, driving a widening nonmetro disadvantage. An alarming finding is that rural women have been especially plagued by rising mortality. Finally, Monnat's analysis underscores the diversity of rural America by showing how the mortality trends differ across Census Divisions and county-level industrial structure.

In "Tracking Urbanization and Exurbs: Migration across the Rural-Urban Continuum, 1990-2016," Shaun Golding and Richelle Winkler highlight migration trends across rural-urban space at the turn of the century. They propose a modified rural-urban continuum classification, the Rural-Urban Gradient (RUG), which holds metropolitan classification constant and distinguishes central city core counties in major metropolitan areas from their suburbs and exurbs. Using county-level migration data from the Internal Revenue Service, they use the RUG to make temporal and regional comparisons of net migration and migration efficiency. Their findings build on migration scholarship by showing that Americans continue to move away from large cities and remote rural areas toward suburban and exurban contexts, noting these trends represent a "sprawling pattern of urbanization, unfurling with particular speed in the American South and to a lesser extent, in the American West."

While most integration and segregation studies are urbancentric-and focused on industrial centers in the Midwest and Northeast in particular-increasing racial and ethnic diversity over recent decades has characterized not only cities but also many suburbs, exurbs, and rural areas across the nation. In "Beyond the City: Exploring the Suburban and Rural Landscapes of Racial Residential Integration across the United States," Ankit Rastogi and Katherine Curtis bring attention to the question of place-based ethnoracial integration. Their study identifies places across the rural-urban continuum that remained stably integrated between the 2000 and 2010 censuses. Results show that the largest clusters of ethnoracial integration during this period were in U.S. suburbs, followed by rural places. Meanwhile, central cities stood as the least integrated places. Moreover, the findings demonstrate that the West is home to more integrated communities than are other regions of the country. These conclusions lead the authors to call for racial inequality scholars to "look outside the city and toward the West" to gain a more complete understanding of the demography of U.S. integration.

It is well recognized that the United States is a comparatively unequal society, and that inequality has been on the rise. The demography of inequality is the focus for Jaclyn Butler, Grace Wildermuth, Brian Thiede, and David Brown who explore "Population Change and Income Inequality in Rural America." Analyzing several decades of county-level data (1980-2016), Butler et al. probe a simple but important question: What are the relative effects of population growth and decline on income inequality within nonmetro counties? With inequality of total household income measured using the Gini Index, they find population loss tends to increase income inequality while population growth mildly decreases it. The pattern is consistent across models and, in the case of population loss, prevails after controls for the sociodemographic and economic characteristics of counties. Echoing a common refrain across studies in this special issue that rural America is not monolithic, Butler et al. 
document and explore regional differences and find, notably, that the link between population loss and increasing inequality is especially apparent in the South.

Rural demographers know well that rurality is a matter of degree. For all its meaning and empirical value, the common use of nonmetro counties as representing rural America comes with important limitations and caveats. Over the years, researchers have responded in different ways to introduce needed nuance. In "Change in U.S. Small Town Community Capitals, 1980-2010," Lori Hunter, Catherine Talbot, Dylan Connor, Miriam Counterman, Johannes Uhl, Myron Gutmann, Stefan Leyk, and Taylor Jaworski take a purposely restrictive definition of rural by focusing on "tiny towns," places with populations of less than 2500 located within nonmetro counties that are completely rural according to ERS. This place-based analysis draws on a variety of data sources to describe sociodemographic change in tiny towns from 1980 to 2010, with attention paid to human capital, natural capital, and other assets suggested by the community capitals framework. Hunter et al. find that tiny towns lost population overall, although this was restricted to those in counties not adjacent to a metro area. They also report that tiny towns, particularly those in nonadjacent counties, are marked by low levels of community capital, a disadvantage that remains consistent over time. Their analysis underscores the policy importance of keeping the nation's most rural places in mind.

Lastly, research has long shown poverty rates to be higher in rural than urban areas using the official federal poverty measure (OPM). However, studies based on the newer Supplemental Poverty Measure (SPM) have challenged this view of rural-urban economic hardship. In "Why is Poverty Higher in Rural America according to the Supplemental Poverty Measure? An Investigation of the Geographic Adjustment," José Pacas and David Rothwell dig into these disparate findings. They show that the different stories produced by the two measures can be largely attributed to the SPM's geographic adjustment for median rent, and that over a third of the SPM's drop in nonmetro areas nationally is driven by the rent adjustment in just six states alone. They conclude that while the SPM is viewed by many as a better measure of poverty than the traditional OPM, researchers should be cognizant of the considerable implications of the housing cost modification for understanding poverty across the rural-urban continuum.

\section{Concluding Observations}

The articles in this special issue document that for rural places otherwise in population decline, Hispanic in-migration constitutes a demographic lifeline for some but not others; chronicle a rising and disturbing rural mortality penalty; probe exurban growth; examine stability and change in ethnoracial integration in rural and urban places; confirm a link between rural population decline and rising income inequality; draw attention to population loss and constrained community capital in America's remote "tiny towns"; and explore how trends in rural poverty are highly sensitive to the measures used.

Collectively, these studies underscore that in the early twenty-first century the demography of rural and small-town America remains in a constant state of change. 
The prospect is for a rural America marked by ever more diversity and inequality within and between places. It is likely, for example, that the ongoing expansion of metro areas and their influence will continue to blur rural-urban distinctions, while also leaving the most remote places behind; some rural areas will grow more ethnoracially diverse and integrated, while these dynamics will be virtually nonexistent in others; and disparities in population health will deepen in concert with rising economic inequalities of rural people and places, though these and other shifts will play out differently across various regions of the country. Taken together, the intersection of rural-urban space and place with other population processes will remain a critical point of focus.

We hope that these articles, and the broader spectrum of scholarship on rural demography they represent, will inspire the next generation of research in this area. As the 2016 election reminded the nation, far from being flyover country, rural America is vitally important politically, socially, culturally, and economically. It is vast and diverse. Demography will continue to have a key role to play in understanding the challenges and opportunities for rural and small-town America in the years ahead.

Acknowledgements This special issue was supported by USDA Multistate Research Project W4001 titled, "Social, Economic and Environmental Causes and Consequences of Demographic Change in Rural America." We also acknowledge the community of scholarship provided by the Population Research Interest Group of the Rural Sociological Society, and the Interdisciplinary Research Network on Rural Population Health and Aging, which is funded by the National Institute on Aging (1R24AG065159). Jensen is also supported by the Population Research Institute at The Pennsylvania State University, which is funded by the Eunice Kennedy Shriver National Institute of Child Health and Human Development (5P2CHD041025-19). We thank Corey Sparks, Kara Joyner, and Dan Lichter for comments on previous versions of this article.

\section{References}

Alonso, W. (1981). Preface. In A. H. Hawley \& S. M. Mazie (Eds.), Nonmetropolitan America in transition (p. xv). Chapel Hill, NC: The University of North Carolina Press.

Bailey, C., Jensen, L., \& Ransom, E. (2010s). Rural America in a globalizing world: Problems and prospects for the 2010s. Morgantown, WV: West Virginia University Press.

Brown, D. L. (2010s). Rural population change in social context. In C. Bailey, L. Jensen, \& E. Ransom (Eds.), Rural America in a globalizing world: Problems and prospects for the 2010s (pp. 299-310). Morgantown, WV: West Virginia University Press.

Cromartie, J. (2017). Rural America at a glance. U.S. Department of Agriculture, Economic Research Service. Retrieved August 31, 2020 from https://www.ers.usda.gov/webdocs/publications/85740/ eib-182.pdf?v=0.

Economic Research Service. (2019). What is rural? Retrieved August 31, 2020 from https://www.ers. usda.gov/topics/rural-economy-population/rural-classifications/what-is-rural/.

Fuguitt, G. V., Brown, D. L., \& Beale, C. L. (1989). Rural and small town America. New York: Russell Sage Foundation.

Gibson, C. (2012). American demographic history chartbook: 1790 to 2010. Retrieved August 31, 2020 from https://www.demographicchartbook.com.

Hines, F. K., Brown, D. L., \& Zimmer, J. M. (1975). Social and economics characteristics of the population in metro and nonmetro counties, 1970. U.S. Department of Agriculture. Agricultural Economic Report No. 272.

Iceland, J. (2014). A portrait of America: The demographic perspective. Oakland: University of California Press. 
Kandel, W. A., \& Brown, D. L. (2006). Population change and rural society. Dordrecht: Springer.

Lichter, D. T., \& Brown, D. L. (2011). Rural America in an urban society: Changing spatial and social boundaries. Annual Review of Sociology, 37, 565-592.

Lichter, D. T., \& Ziliak, J. P. (2017). The rural-urban interface: New patterns for spatial interdependence and inequality in America. Annals of the American Academy of Political and Social Science, 672, $6-25$.

Monnat, S. M., \& Brown, D. L. (2017). More than a rural revolt: Landscapes of despair and the 2016 Presidential election. Journal of Rural Studies, 55, 227-236.

U.S. Census Bureau. (2015). Urban and rural populations: 1790-1990. Retrieved July 28, 2020 from https ://www.census.gov/population/www/censusdata/files/table-4.pdf.

U.S. Census Bureau. (2020). Rural America: How does the Census Bureau define rural? Retrieved August 31, 2020 from https://gis-portal.data.census.gov/arcgis/apps/MapSeries/index.html?appid $=7 \mathrm{a} 41374 \mathrm{f} 6 \mathrm{~b} 03456 \mathrm{e} 9 \mathrm{~d} 138 \mathrm{cb} 014711 \mathrm{e} 01$.

Publisher's Note Springer Nature remains neutral with regard to jurisdictional claims in published maps and institutional affiliations. 